\title{
POLÍTICAS PÚBLICAS PARA MULHERES: UMA VERIFICAÇÃO IN LOCO DAS CONTRIBUIÇÕES DO PROGRAMA "MULHERES SIM" NO EMPODERAMENTO DAS ESTUDANTES DO IFSC - CÂMPUS SÃO MIGUEL DO OESTE
}

\author{
PUBLIC POLICIES FOR WOMEN: AN IN LOCO VERIFICATION \\ OF THE CONTRIBUTIONS OF THE "WOMEN YES" PROGRAM \\ ON EMPLOYMENT OF IFSC STUDENTS - SÃO MIGUEL \\ CAMPUS IN THE WEST.
}

Jacinta Lúcia Rizzi Marcom (jacinta.marcom@ifsc.edu.br.); Idianes Tereza Mascarelo (idianes.mascarelo@ifsc.edu.br.); Maristella Leticia Selli (maristella.mallmann@ifsc.edu.br)

\begin{abstract}
RESUMO
O presente artigo relata uma experiência desenvolvida no Instituto Federal de Santa Catarina - IFSC, câmpus São Miguel do Oeste, em que se descreve a realização do programa "Mulheres SIM", intitulado: Curso de Educação e gênero: Mulheres haitianas e brasileiras na construção da cidadania numa perspectiva intercultural, bem como se discute as influências do programa na vida dessas mulheres, problematizando sobre as contribuições ou não na melhoria da qualidade de vida das estudantes.
\end{abstract}

\section{PALAVRAS-CHAVE}

Empoderamento. Inclusão social. Políticas Públicas. Educação.

\section{RESUMEN}

El presente artículo relata una experiencia desarrollada en el Instituto Federal de Santa Catarina IFSC, en el marco del programa "Mujeres SIM", titulado: Curso de Educación y Género: Mujeres haitianas y brasileñas en la construcción de la ciudadanía bajo una perspectiva intercultural, así como discute las influencias del programa en la vida de esas mujeres, problematizando sobre las contribuciones o no en la mejora de la calidad de vida de las estudiantes.

\section{PALABRAS CLAVE}

Empoderamiento. Inclusión social. Políticas públicas. Educación. 


\begin{abstract}
This article reports on an experience developed at the Federal Institute of Santa Catarina - IFSC, São Miguel do Oeste Campus, which describes the implementation of the "SIM Women" program, entitled: Education and gender: Haitian and Brazilian women in the building of citizenship in an intercultural perspective, as well as discusses the influence of the program on the lives of these women, problematizing about the contributions or not in improving the quality of life of students.
\end{abstract}

\title{
KEYWORDS
}

Empowerment. Social inclusion. Public policy. Education.

Este estudo está constituído de três seções: na primeira apresentase o contexto do programa "Mulheres SIM" enquanto política pública, incluindo as premissas necessárias para fundamentar o tema; na segunda, aborda-se o trabalho desenvolvido especificamente no câmpus de São Miguel do Oeste através do programa citado, e por fim, na terceira seção, discutem-se os impactos do programa na vida das mulheres participantes.

Considerando o programa Mulheres Sim como política pública temse claro a necessidade de ações desenvolvidas pelo Estado para garantir a prática dos Direitos Humanos previstos pela Constituição (1988). Art. $5^{\mathbf{0}}$ "Todos são iguais perante a lei, sem distinção de qualquer natureza, garantindo-se aos brasileiros e aos estrangeiros residentes no País a inviolabilidade do direito à vida, à liberdade, à igualdade, à segurança e à propriedade [...]". O programa Mulheres Sim se caracteriza por ser uma política pública de gênero para mulheres, essencialmente as que se encontram em vulnerabilidade, sendo essa ação uma das formas de inclusão social, econômica e educacional, também é considerada a saúde da mulher e de sua família primando essencialmente pelo empoderamento da mulher brasileira e haitiana, elevando sua autoestima e autonomia, inserindoas no mercado de trabalho. Nesse sentido, de acordo com Prá (2006, p. 40) "o empoderamento da mulher se refere ao poder e às relações dentro da sociedade que se entrecruzam com o gênero, a classe social, a raça, a cultura e a história". 
Quanto ao trabalho desenvolvido no câmpus de São Miguel do Oeste, situado no oeste de Santa Catarina - Brasil pode-se afirmar que o município, como outros da região, vivem uma realidade em que chegam muitos haitianos em busca de melhores condições de vida. O IFSC, visando cumprir com sua missão de promover a inclusão e formar cidadãos difundindo e aplicando conhecimentos, propôs uma prática transformadora através do programa de Formação Inicial e Continuada "Mulheres SIM" intitulado: "Curso de Educação e gênero: Mulheres haitianas e brasileiras na construção da cidadania numa perspectiva intercultural" visando entrelaçar os conhecimentos trazidos pelas duas culturas. Se o papel social da mulher é fundamental para o fortalecimento de laços na sociedade contemporânea, o presente espaço educativo visa oportunizar a construção de autonomia e geração de renda para um grupo de 15 (quinze) mulheres haitianas e 15 (quinze) brasileiras. Em sala de aula os docentes construíram trocas de saberes interculturais com foco no conhecimento histórico-cultural, saúde da mulher e da família, ética e cidadania, linguagens, informática, desenvolvimento social e sustentável, vivência matemática e geração de renda.

O Programa Mulheres SIM é uma ação de extensão do IFSC vinculados à $\mathrm{PROEX}{ }^{1}$, que busca a valorização da mulher, o acesso aos direitos, cidadania e possibilidades de geração de renda, ou seja, o empoderamento feminino. O programa é destinado a um públicoalvo: mulheres que possuem mais de 15 anos, em vulnerabilidade social e, preferencialmente, sem escolaridade.

Desde 2014 a atividade está sendo desenvolvida com públicos estratégicos: mulheres cadastradas do Centro de Referência da Assistência Social - CRAS, mulheres em vulnerabilidade social, mulheres agricultoras, mulheres brasileiras e haitianas. Em relação a realização do programa no decorrer dos anos percebe-se que seu objetivo aborda a necessidade de proporcionar a construção de conhecimentos que auxiliem as alunas no exercício da cidadania, na melhoria de sua qualidade de vida e de sua família, e que contribuam para a geração de renda, a partir do desenvolvimento de atividades embasadas no saber já adquirido, abordando temas contextualizados e de impacto direto no seu dia a dia.

1 A Pró-Reitoria de Extensão e Relações Externas (Proex) é responsável por planejar, desenvolver, controlar e avaliar as políticas de extensão, de integração e de intercâmbio do IFSC com o setor produtivo e a sociedade em geral e coordenar os processos de divulgação e de comunicação institucional. 
Sobre o itinerário formativo do programa pode-se relatar que contemplou as seguintes temáticas: Educação e gênero, Feira de Econômica Solidária e Ciclo de palestras e oficinas. Quanto à Educação e gênero destaca-se a necessidade de motivar a autonomia e a geração de renda, envolvendo temas como: Conhecimento histórico-cultural; Saúde da mulher e da família; Ética e cidadania; Linguagens; Informática; Desenvolvimento social e sustentável; Vivência matemática; Geração de renda e da família; Ética e cidadania; Linguagens; Informática; Desenvolvimento social e sustentável; Vivência matemática; Geração de renda (Artesanato, Boas práticas para manipuladores de alimentos e Olericultura/Plantas medicinais).

A Feira de Econômica Solidária teve como objetivo o fomento às práticas sustentáveis que promovam o realinhamento e o fortalecimento do desenvolvimento local e a educação inclusiva. Configura-se como uma prática pedagógica em que as alunas se envolveram desde a produção dos materiais até venda dos mesmos, contribuindo assim para a elevação de renda e promoção da inclusão produtiva e social de mulheres.

No Ciclo de palestras e oficinas as temáticas estão relacionadas aos direitos humanos, direitos trabalhistas, saúde da mulher e da família, prevenção à violência contra a mulher, plantas medicinais e temperos (complementação da Unidade Curricular Geração de renda: Olericultura/ Plantas medicinais, proposto no curso), penteados e desfile (reforçam a cultura haitiana e afrodescente, a autoestima e o sentimento feminino), comidas típicas haitianas e brasileiras: trocas de sabores e saberes.

Esse itinerário formativo foi construído como suporte teórico para o programa, de modo a contribuir para que as mulheres estudantes experienciem através da formação escolar possibilidades de construírem seu empoderamento pessoal e profissional.

A proposta se materializou através de três importantes momentos: o acolhimento, as aulas/ oficinas e feira de economia solidária. O acolhimento dessas mulheres aconteceu no mês de junho/2018 através da realização de uma aula inaugural (Figura 1 e 2). Este espaço contou com atividades de socialização e integração entre as estudantes e os docentes do curso. 


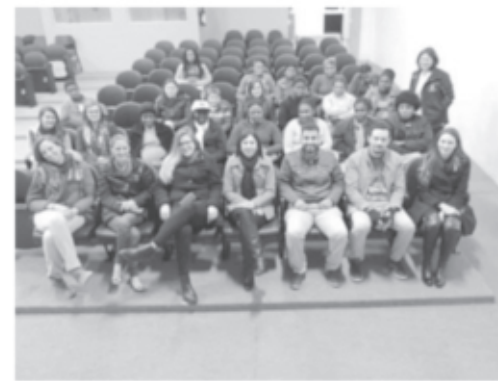

Figura 1 - Recepção das estudantes

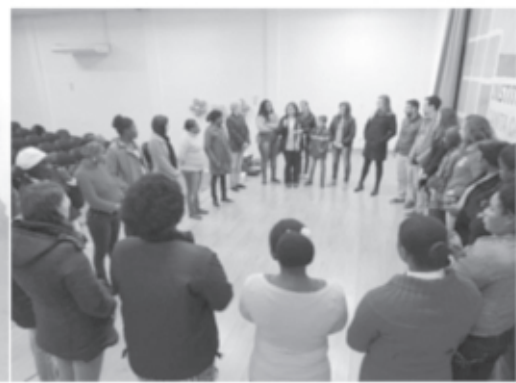

Figura 2 - Dimâmica de recepção das estudantes

Em seguida, visando conhecer a realidade, foi realizada uma entrevista com as estudantes do referido programa, que posteriormente serviu de base para discutir e escolher as melhores estratégias de ensinoaprendizagem para desenvolver o trabalho proposto com as mulheres estudantes.

Dando continuidade ao relato sobre o programa, as alunas foram convidadas a participar de dois encontros presenciais semanais através dos quais tiveram acesso às oficinas, aulas de laboratórios, aulas práticas de campo e aulas de teóricas das unidades curriculares que compuseram o curso (Figuras 3, 4 e 5).

Sobre as atividades desenvolvidas em sala de aula pelo programa intitulado "Mulheres haitianas e brasileiras na construção da cidadania numa perspectiva intercultural", sinaliza-se a importância da relação constituída entre as mulheres e o Instituto Federal de Educação - IFSC, Câmpus São Miguel do Oeste. Durante a realização de um momento de integração elas relataram três aspectos bastante significativos: que antes de frequentar o curso não se sentiam parte do câmpus, ou seja, achavam que os bancos escolares do Instituto Federal de Santa Catarina - IFSC estariam longe de suas realidades, relataram também a satisfação em participar das atividades propostas e por fim, reforçaram as contribuições do programa para o próprio empoderamento pessoal, profissional e social. 
Nestas três proposições observa-se nitidamente que, até alguns anos atrás, a educação era privilégio de poucas mulheres, entretanto, mesmo tendo essa oportunidade na contemporaneidade olham para a instituição escolar e não se reconhecem nela. Cabe pensar e ousar questionar o porquê isso acontece? Quais os fatores que contribuem para que esse reconhecer-se se materialize nas oportunidades que a escola oferece para as minorias? Em determinada oportunidade as falas das estudantes dão base para compreender que não basta apenas abrir as portas da sala de aula e oferecer-lhe um curso, faz-se prudente que este espaço desconstrua os estereótipos criados no decorrer dos anos. Propõe-se esta reflexão a partir de incursões feitas pelas estudantes, quando de sua matrícula no IFSC - Câmpus São Miguel do Oeste: "A gente pode estudar aqui?", "Quanto se paga pra isso?", "Meu Deus, é um sonho esta escola".

É nítida a incorporação destes pré-conceitos com relação ao exercício de sua própria cidadania, não sentindo-se capazes de exigir que lhe sejam garantidos os direitos constitucionais, dentre eles, a educação, a saúde, o respeito, a dignidade, etc. O IFSC - Câmpus São Miguel do Oeste, como muitas outras instituições de ensino, oferece um ensino de qualidade, e que até mesmo, sua estrutura física dá conta de ser um espaço atraente. Neste horizonte, busca-se através de um itinerário formativo dar a estas mulheres o importante espaço de empoderamento. Ademais, após seu ingresso e acolhimento na instituição frisam sua satisfação pela oportunidade, compreendendo essa oportunidade como um dos pilares para a formação cidadã.

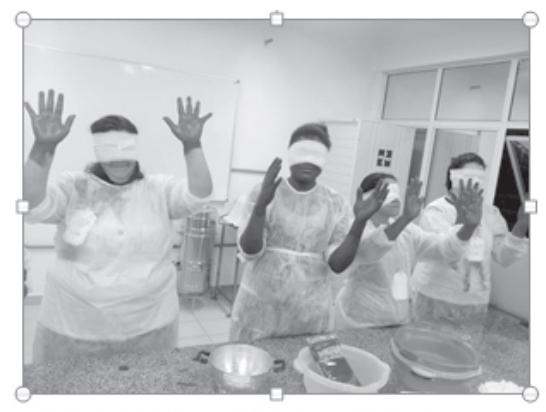

Figura 3 - Oficina de higienização das mãos

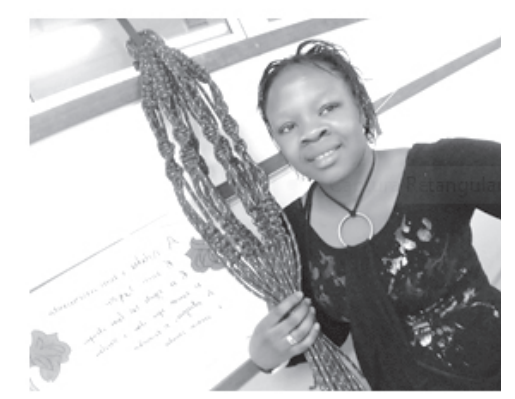

Figura 4 - Oficina de artesanato 


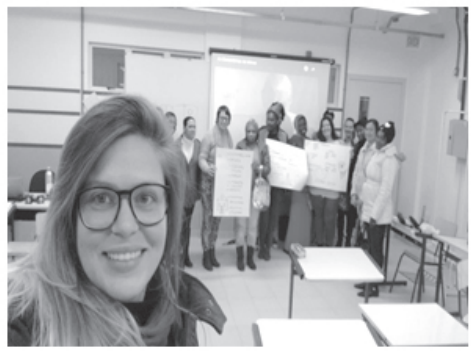

Figura 5 - Aula de Ética e cida dania

E, como terceiro momento, organizou-se a feira de economia solidária envolvendo a comunidade local (Figuras 6 e 7). Através de sua realização, as mulheres foram inseridas em um ambiente capaz de vivenciar experiências relacionadas ao mercado de trabalho. Entende-se que esse é um momento ímpar de percepção da relação teoria e prática, além de mostrar as estudantes do curso formas de qualificar a interação com a comunidade e a geração de renda para sua família. Define-se como importante este momento considerando que as mulheres haitianas que chegam ao Brasil não encontram muitas possibilidades de trabalho e, da mesma, forma as mulheres brasileiras ainda possuem muitas conquistas para ocupar o seu verdadeiro papel em uma sociedade que não faça diferença entre homens e mulheres.

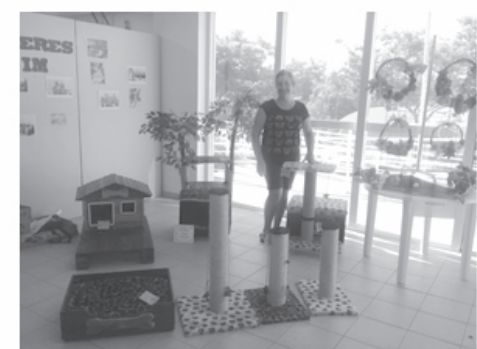

Figura 6 - Feira de Economia solidánia

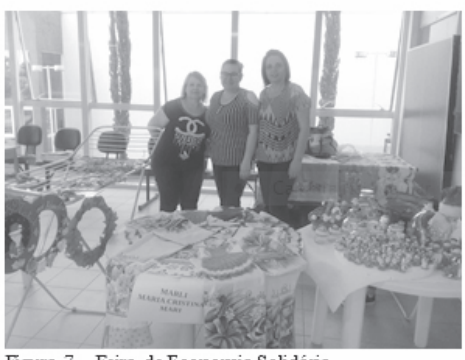

Figura 7 - Feira de Economia Solidána

Destaca-se que sazonalmente ocorreu a presença das crianças junto com as mulheres estudantes e mães haitianas, isso nos remete à reflexão dos diferentes papéis sociais e familiares que a mulher precisa desempenhar (figura 8). 


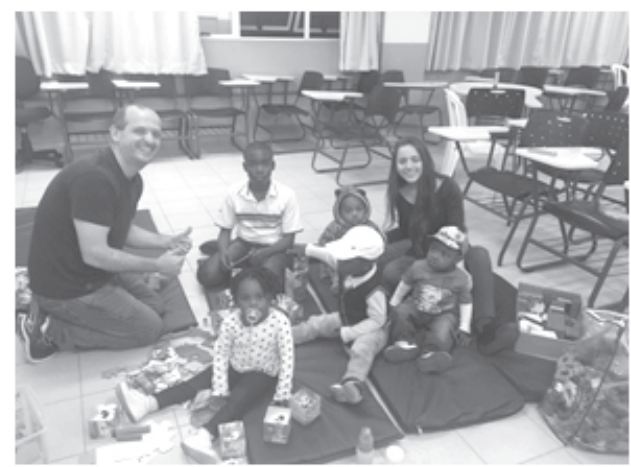

Figura 8-Atividades com os filhos das estudantes

Ainda dialogando sobre as contribuições ou não do programa, apresentam-se, na sequência, os dados coletados através de uma pesquisa realizada com as estudantes no início do semestre letivo, ressalta-se que as informações serão apresentadas de acordo com a relevância sobre o tema estudado.

\section{ANÁLISE DOS DADOS PESQUISADOS COM AS MULHERES DO PROGRAMA MULHERES SIM 2018 - AS CONTRIBUIÇÕES PARA O EMPODERAMENTO DO PÚBLICO ALVO}

Sobre o perfil das estudantes, registra-se que o grupo é composto por mulheres cuja faixa etária encontra-se entre 20 a 29 anos (Figura 9 - A). Outro fator que chama atenção no perfil das mesmas é o fato de que $57 \%$ delas possui apenas um filho (Figura 9 - B). A pesquisa apontou também que $40 \%$ delas possuem apenas o ensino fundamental incompleto. Outro dado interessante é que $86 \%$ das entrevistadas precisaram interromper os estudos em algum momento da vida, principalmente na adolescência sendo que $37 \%$ apontaram este resultado, justificando que o motivo principal foi a necessidade de trabalhar (Figura 9 - C). A renda que recebem é oriunda de benefícios sociais: bolsa família, Benefício de Prestação Continuada, dentre outros, isso apontado em 33\% das respondentes, seguido de $21 \%$ que possuem emprego com carteira assinada ou são servidoras públicas (Figura 9 - D). 
Nesse contexto, observa-se um público jovem, com famílias constituídas e como consequência possuem baixa renda e pouca escolaridade. Apontase que essa realidade traz a lume situações críticas de violência doméstica, pobreza, abandono ocasionando baixa qualidade de vida.

As oscilações que historicamente têm marcado a trajetória das mulheres no espaço público revelam que as construções culturais apoiadas, ainda hoje, na essência e natureza femininas tem sido determinantes para estabelecer e sustentar as diferenças nas posições ocupadas por homens e mulheres na família, educação, trabalho e outros espaços da vida social (REIS, 1993.p. 7).

O Instituto Federal de Educação - câmpus São Miguel do Oeste, sensibilizado por tal realidade do papel da mulher na sociedade, ofereceu esse curso, reforçando o compromisso social apresentado nas diretrizes do Projeto Pedagógico Institucional em que reforça a necessidade de apoiar e desenvolver projetos sociais de inclusão e de tecnologias sociais (figuras 10 e 11), atendendo preferencialmente as populações e comunidades em situação de vulnerabilidade social.

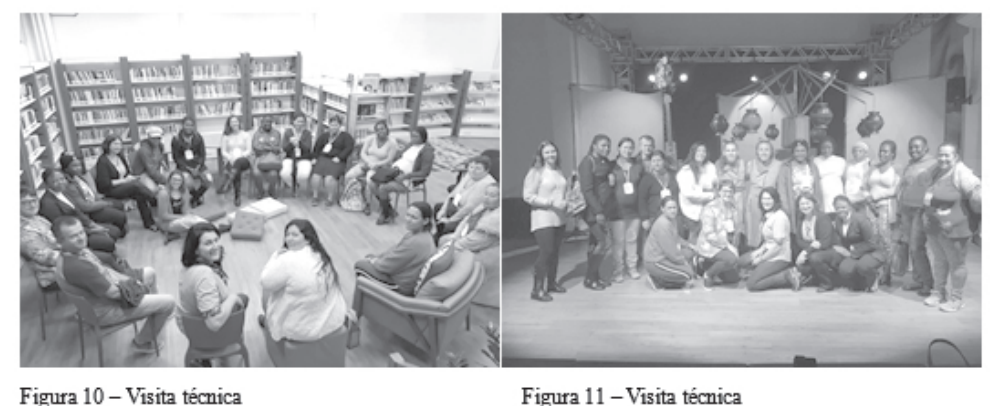

Alicerçados nos valores do IFSC que pautam-se na ética, compromisso social, equidade, democracia, sustentabilidade e qualidade reafirmamos a relevância da educação enquanto agente transformador da realidade social. Concordando com Freire (1980, p. 39), "[...] é preciso que a educação esteja - em seu conteúdo, em seus programas e em seus métodos - adaptada ao fim que se persegue: permitir ao homem chegar a ser sujeito, construirse como pessoa, transformar o mundo, estabelecer com os outros homens relações de reciprocidade, fazer a cultura e a história. 
De acordo com Freire, também considerando as falas das mulheres, em entrevistas realizada pelo programa, enfatiza-se que a instituição procura cumprir seu papel quanto ao processo ensino-aprendizagem e seu compromisso em formar cidadãs capazes de intervir na sociedade em que fazem parte.

Quando questionadas se gostariam de continuar os seus estudos $86 \%$ delas afirmaram que "sim" (Figura 9 - E). Também 95\% gostariam de continuar seus estudos no IFSC, o que aponta o desejo dessas mulheres em buscar formação, entretanto não o fizeram por falta de suporte familiar, social, econômico e cultural (Figura 9 - F).
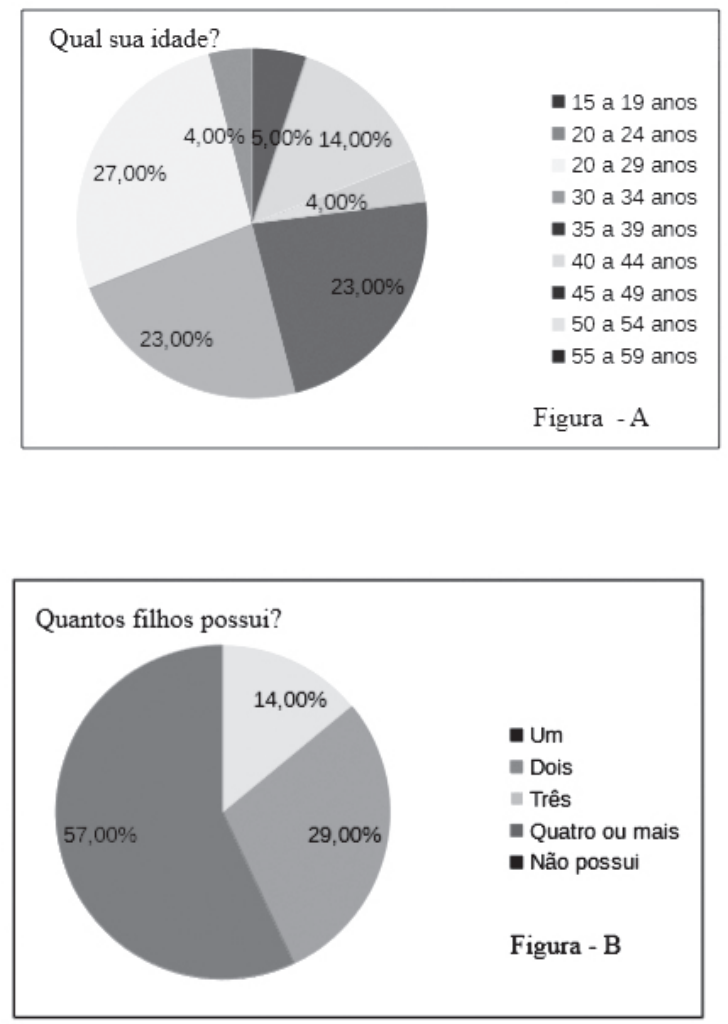

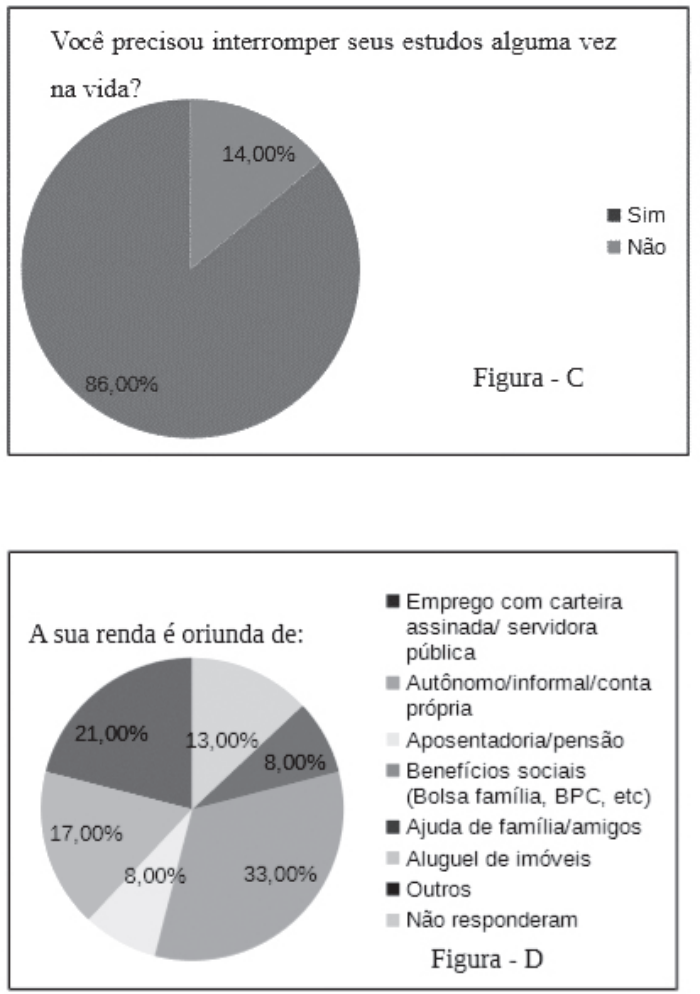

Você gostaria de continuar seus estudos?
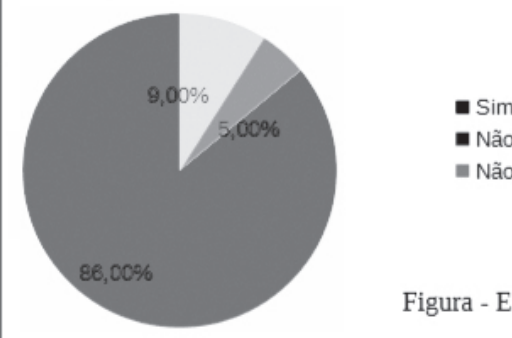

- Não

não responderam

Figura - E 


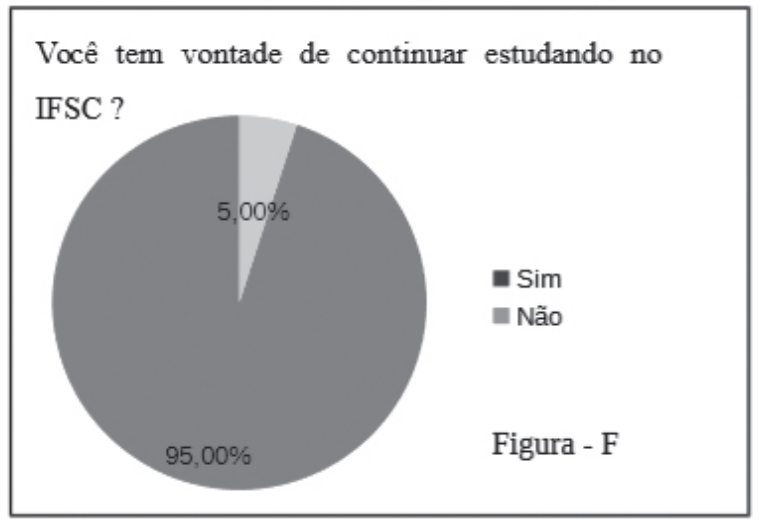

Figura 9 - Pesquisa realizada com as alunas participantes do programa Mulheres $\mathrm{SIM} / 2018$.

É importante salientar que a as políticas educacionais inclusivas podem interferir na vida destas mulheres, de acordo com um docente que atuou no programa, relata-se:

Trabalhei com o grupo do Projeto "Mulheres Sim" a componente curricular Ética e Cidadania. Foi uma experiência diferente. Apesar de já atuar como professor há mais de 20 anos, jamais havia trabalhado com um grupo heterogêneo como este, com pessoas de nacionalidades diferentes. Optei por desenvolver temas como direitos humanos, mostrando de que forma eles são resultados de processos de lutas coletivas e conquistas históricas e procurando associar a ideia de direitos com as condições histórico sociais vividas pelas alunas. Associei com os temas "racismo e preconceitos" e desigualdade de gênero, destacando o machismo e a violência contra a mulher. De um modo geral ficou visível que o grupo de alunas, tanto as brasileiras, quanto as haitianas, experimentaram em graus e níveis diferentes diversas formas de violência física e, principalmente simbólica, tendo vivido experiências de negação dos direitos humanos básicos. Me surpreendeu o fato de que elas falam das experiências pessoais de forma bastante espontânea, sem constrangimentos por fazer relatos pessoais. Observei, no entanto, que possuíam níveis de consciência bastante distintos acerca da própria condição. Enquanto algumas manifestaram claramente uma consciência da vulnerabilidade da própria condição, outras reproduzem a ideologia dominante, atribuindo a condição social em que vivem, a fracassos e 
escolhas pessoais equivocadas. Nem todas conseguem associar a trajetória de vida pessoal com oportunidades e condições ofertadas. Muitas entendem que o sucesso ou o fracasso pessoal é resultado da mais pura meritocracia e, por isso, se posicionam contrárias até mesmo às políticas sociais que as favorecem. Quanto a interação entre brasileiras e haitianas, observei que não se deu de forma totalmente espontânea. Por isso, nas atividades em grupo, optei por estabelecer uma mistura de brasileiras com haitianas. Observei que a dificuldade da interação se dava mais por conta do idioma, já que nem todas as haitianas dominam o português, do que por outras razões. De um modo geral, a experiência foi gratificante, inspiradora e desafiadora (PROFESSOR A).

Com base nas considerações do PROFESSOR A, faz-se mister destacar a importância da oportunidade que estas mulheres tiveram, no sentido de superar seus próprios limites na busca constante por espaço na sociedade, na família, na escola, contribuindo assim, para o empoderamento feminino. Sabe-se que as mulheres estão imersas em um mundo que constantemente se ouve prática de abuso, racismo, morte e violência contra elas. Assim, percebemos a necessidade de para além do trabalho educativo atingir o seu entorno familiar.

Salientamos que é um dos anseios dos envolvidos na referida ação de extensão, que se trabalhe também na situação que envolva os respectivos cônjuges e companheiros.

Diante deste panorama outro fator vem à tona: acrescenta-se a necessidade de reflexão quanto às dificuldades encontradas pela instituição em trabalhar com a diversidade, focando aqui, a interculturalidade e as diferenças sociais, culturais, étnicas e econômicas que estão incorporadas à vida das estudantes que frequentaram o curso.

\section{CONCLUSÃO}

Ao concluir as reflexões sobre as possibilidades da experiência citada, destacamos:

1. Através do acesso ao conhecimento as mulheres estudantes do programa buscaram uma oportunidade de empoderar-se e conquistar seu espaço na sociedade, pois é através do domínio do saber que se universalizam os direitos e se estabelece a proteção às minorias; 
2. O Instituto Federal de Santa Catarina (IFSC) enquanto instituição educacional possui como missão formar cidadãos, por meio da educação profissional contribuindo com o desenvolvimento cultural, econômico e social, o que se materializou durante os três meses em que estas mulheres estiveram na instituição, entretanto, percebeu-se que para além deste tempo, é fundamental a existência de políticas públicas em nível de governo para amparar os imigrantes e os brasileiros em vulnerabilidade na defesa do direito à vida, a saúde, a educação, dentre outros;

3. Os professores da instituição tiveram um grande desafio para ministrar suas aulas às estudantes haitianas em função da falta de domínio da língua, além da dificuldade de integrar as estudantes brasileiras com as haitianas, por conta da resistência demonstrada no decorrer do processo de socialização mesmo com o uso de diferentes metodologias diferenciadas, isso nos remete ao fato de que as instituições de ensino nem sempre dão conta do mosaico da intercultural idade;

4. Outro elemento importante observado foi a necessidade de resgatar nas mulheres a autoestima, fazendo-as perceberem que seu papel é imprescindível para diminuir os casos de violência doméstica, direitos sociais, machismo, exclusão, uma vez que elas saem do curso com o domínio de conhecimentos essenciais para se fazer respeitar enquanto mulher cidadã. Por outro ângulo, percebeu-se a necessidade e a essencialidade de oportunizar a inserção do homem no programa de forma a inclúi-lo nas atividades, propostas garantindo com isso maior amplitude na conquista dos objetivos propostos pelo projeto pedagógico do curso descrito;

5. Ainda, mesmos com todos os percalços, avista-se que estas mulheres participantes do programa, especialmente as haitianas deixam transparecer uma sensação de segurança, de aconchego e de oportunidade quando o IFSC abre as portas para este acolhimento. Xiberras (1996, p. 9) afirma que "as situações de fragilidades social, às quais as mulheres estão inseridas, são frequentemente caracterizadas por ameaças de ruptura do laço social de proximidade e de solidariedade [...], acarretando frequentemente acumulação de insucesso, rejeição e exclusão social". Ademais, é neste contexto que propomos trazer condições favoráveis para que o público alvo de nossa experiência, e seu entorno, possam ter melhores condições de vida. 
6. Concordamos com as palavras de Freitas (2009, p. 111) que considera ser a educação importante ferramenta, pois, é através dela que se pode "favorecer um maior autoconhecimento, um melhor conhecimento do outro, que ela poderá reduzir intolerâncias nas suas diversas faces, que pode gerar uma humanidade mais acolhedora à sua própria diversidade". Neste contexto, foi contudo, aquilo que construímos e difundimos nas atividades que foram executadas.

\section{REFERÊNCIAS}

Brasil (2019). Constituição da República Federativa do Brasil (1988). Promulgada em 05 de outubro de 1988. Disponível em: <www. planalto.gov.br/ccivil_03/constitui... Acesso em: 25 fev. 2019.

Freire, P. (1980). Conscientização: teoria e prática da libertação - uma introdução ao pensamento de Paulo Freire. 4. ed. São Paulo: Moraes.

Freitas, M. E. de. (abr/jun. 2009). A mobilidade como novo capital simbólico nas organizações ou sejamos nômades? Organizações \& Sociedade, Salvador, v. 16, n. 49, p. 247-264.

Prá, J. (2006). Políticas públicas, direitos humanos e capital social. Ijuí: Unijuí.

Reis, Maria Cândida Delgada (1993). Tessitura de Destinos: mulher e educação. São Paulo: EDUC. 